Research Paper

\title{
Donor polymorphisms of Rapl A rs494453 contribute to a higher risk of hepatocellular carcinoma recurrence following liver transplantation
}

\author{
Rulin Zhang ${ }^{1 *}$, Junyi $\mathrm{Wu}^{2 *}$, Yiming Yang ${ }^{3 *}$, Dongge $\mathrm{Xia}^{1}$, Jiayong $\mathrm{Li}^{1}{ }^{1}, \mathrm{Heng}$ Quan ${ }^{1}$, Ziguang Niu${ }^{1}$, Ye \\ Yang $^{4}$, Jun $\mathrm{Wu}^{1,5 \bowtie}$ \\ 1. Department of Laboratory Medicine, Shanghai General Hospital, Shanghai Jiao Tong University, Shanghai, People's Republic of China \\ 2. Department of General Surgery, Shanghai General Hospital, Shanghai Jiao Tong University, Shanghai, People's Republic of China \\ 3. School of Life Science, Shanghai University, Shanghai, People's Republic of China \\ 4. Department of Gastroenterology, HwaMei Hospital, University of Chinese Academy of Sciences, Ningbo, People's Republic of China \\ 5. Department of Biochemistry and Molecular Cell Biology, Shanghai Jiao Tong University School of Medicine, Shanghai, People's Republic of China \\ *Rulin Zhang, Junyi Wu and Yiming Yang contributed equally to this work
}

$\triangle$ Corresponding authors: Jun Wu, Ph.D., Department of Laboratory Medicine, Shanghai General Hospital, Shanghai Jiao Tong University, 100 Haining Rd., Shanghai 200080, People's Republic of China. Telephone: +86-021-63240090; Email: jun.wu@shsmu.edu.cn and Ye Yang, M.D., Department of Gastroenterology, HwaMei Hospital, University of Chinese Academy of Sciences, 41 Xibei St., Ningbo 315010, People's Republic of China. Telephone: +86-0574-83871152; Email: 625399581@qq.com.

(c) The author(s). This is an open access article distributed under the terms of the Creative Commons Attribution License (https://creativecommons.org/licenses/by/4.0/). See http://ivyspring.com/terms for full terms and conditions.

Received: 2019.08.28; Accepted: 2020.01.20; Published: 2020.03.04

\begin{abstract}
Background: Hepatocellular carcinoma $(\mathrm{HCC})$ recurrence appears commonly after liver transplantation (LT), and it severely affected the long-term survival of patients. Previous studies have proved that RaplA is involved in hepatocarcinogenesis and metastasis, and demonstrated the significant association between RaplA gene rs 494453 polymorphism and HCC. However, the relationship between RaplA rs 494453 polymorphism and HCC recurrence after LT remained unclear.

Methods: A total of $74 \mathrm{HCC}$ patients who underwent LT from July 2005 to June 2015 was analyzed. The genotypes of both donors and recipients had been confirmed as Rap IA rs494453. The independent risk factors that associated with $\mathrm{HCC}$ recurrence were investigated with univariate and multivariate logistic regression analysis. The recurrence-free (RFS) and overall survival (OS) were calculated with Cox regression analysis. The RaplA rs 494453 genotype frequencies were determined using the $X^{2}$ test and the minor allele frequencies (MAFs) of Rap1A rs494453 genotypes were calculated by Hardy-Weinberg equilibrium.
\end{abstract}

Results: We found that the donor Rap IA rs 494453 polymorphism was profoundly associated with HCC recurrence after LT. Moreover, the Milan criteria, microvascular invasion and donor RaplA rs 494453 genotype were proved to be independent risk factors for $\mathrm{HCC}$ recurrence. Patients with donor AG/GG genotypes had a distinct lower RFS and OS than AA genotype. The TNM stage, Milan criteria, microvascular invasion, and donor Rap IA rs494453 genotype were independent factors for the RFS of LT patients.

Conclusions: Donor RaplA rs494453 is a potential predictive marker for HCC recurrence risk after LT.

Key words: Rap1A polymorphism, hepatocellular carcinoma, recurrence, liver transplantation

\section{Introduction}

Hepatocelluar carcinoma (HCC) is one of the major cancer-related death causes [1]. The main features of HCC include rapid progression, poor prognosis, and frequent tumor recurrence. Among novel therapies, the orthotopic liver transplantation (LT) is still considered the best treatment for HCC 
patients having cirrhosis syndrome without local or distant metastasis [2].

However, the recurrence after LT remains frequently among $1.3 \%$ to $44.9 \%$, which depends on individual series [3,4]. Abundant studies have concluded the main causes for high HCC recurrence after surgery, including microvascular invasion, poor tumor grade, larger tumor diameter, ischemia time, vascular invasion and elevated AFP [5-7]. These factors are viewed to be significant prediction of HCC recurrence by famous institute, such as the Milan, University of California San Francisco (UCSF), and Hangzhou criteria $[8,9]$.

Rap1A is a member of Ras oncogene family of small $G$ protein, which regulates different cellular processes, including proliferation, adhesion and cancer progression. It was reported that Rap1A promoted ovarian cancer tumorigenesis and metastasis via activating ERK, MAPK, Notch pathways [10]. Decreasing Rap1A suppressed cell proliferation, adhesion, and invasion in prostate cancer and several other cancer types [11-13]. A recent study further demonstrated that Rap1A expression abolished the tumor-suppressive effects of EYA4 in HCC cells, which could promote the proliferation and recurrence [14]. In clinical studies, Rap1A is not only overexpressed in a cohort of Oral Cavity Squamous Cell Carcinoma (OCSCC) specimens but also correlated with the clinical characteristics of the advanced tumor stage [13]. As Rap1A plays important role in malignancies, it is worthy to understand the relationship between Rap1A expression and HCC recurrence after LT.

Patients who underwent LT were divided into recurrence group and nonrecurrence group for comparation, to identify the clinicopathological factors associated with the poor prognosis. Rap1A genotypes were observed to have function on HCC relapse. Hence, we endeavoured to uncover whether donor or recipient HCC susceptibility gene (Rap1A) variations contribute to the HCC recurrence after LT in a Han Chinese population.

\section{Materials and Methods}

\section{Patients}

We collected 74 HCC patients among Han Chinese undergoing LT from July 2005 to June 2015 at the department of liver transplantation Surgery, Shanghai General Hospital, Shanghai, China. The median age was 47.3 years (range from 32-66 years), including 65 males and 9 females. The mean follow-up period was 49.2 months (range from 2.3-120 months). The LT criteria for patients with HCC included the absence of extrahepatic malignancies, macroscopic tumor thrombosis, and extrahepatic metastasis of HCC.

Patients were treated with standard immunosuppression regimen consisting of the triple drugs combination of cyclosporin (CsA) or tacrolimus (FK506), mycophenolate (MMF) and prednisone. Lamivudine and hepatitis B immune globulin (HBIG) were used for HBV DNA positive patients to prevent hepatitis $B$ recurrence. The antineoplastic prophylaxis of chemotherapy and targeted therapies was used for certain patients. All patients were asked to monitor tumor recurrence or metastasis by undergoing the AFP test, ultrasonography, chest X-ray, and emission computed tomography every three months for the first two years and semiannually thereafter.

\section{Ethics statement}

Organ donation and transplantation were approved by the Institutional Review Board, Shanghai General Hospital, and carried out strictly under the guidelines of the Ethics Committee of the hospital, and Declaration of Helsinki. All patients provided written informed consent.

\section{Data collection}

Clinicopathological data such as age, sex, hepatitis B status, cirrhosis, histologic grade (well differentiated, moderately differentiated and poorly differentiated), Milan criteria, TNM stage, tumor size, multinodular status, microvascular invasion, and pre-LT serum AFP level were recorded. The pre-transplant data were all collected within $24 \mathrm{~h}$ before transplantation.

\section{DNA Isolation and Polymorphism Genotyping}

LT patients were divided into two groups, patients with HCC recurrence and nonrecurrence control groups. These samples were previously stored at $-80^{\circ} \mathrm{C}$ before being genotyped. DNA was isolated from EDTA-anticoagulated whole blood or liver tissues of donors and recipients using the AllPrep DNA/RNA Mini kit (Qiagen, Venlos, the Netherlands). PCR reaction system (10 ul) included $1 \times G C$ buffer, $3.0 \mathrm{mM} \mathrm{Mg}{ }^{2+}$, $0.3 \mathrm{mM}$ dNTP, 1 U HotStarTaq polymerase, $1 \mathrm{ul}$ templates DNA and $1 \mathrm{ul} \mathrm{PCR}$ primer pair: $5^{\prime}$ CAGAAGCTGGTGGAGTGGG $3^{\prime}$ and $5^{\prime}$ ACCTGGATAGACGCTGGCC $3^{\prime}$. The conditions of PCR amplification and the mass extension reaction were available on request. Genotyping was performed in a blind way. To assess the reliability of genotyping, we randomly choose more than $10 \%$ of the samples to sequence twice. Single nucleotide polymorphism (SNP) genotyping was executed using a Sequenom Mass ARRAY SNP genotyping platform (Sequenom, San Diego, CA) [15]. 


\section{Statistical analysis}

Statistical analysis was performed with SPSS statistical software version 21.0 (SPSS Inc., Chicago, IL, USA). Quantitative variables were denoted as medians $( \pm \mathrm{SD})$ and compared using Student's t-test or the Wilcoxon signed-rank test. Categorical variables were expressed as values (percentages) and compared by Pearson's $X^{2}$ test or Fisher's exact test. The allele and genotype frequencies were determined using the $\mathrm{X}^{2}$ test. SHEsis Online Version (http://analysis.bio-x. $\mathrm{cn} /$ myAnalysis.php) was used to analyze HardyWeinberg equilibrium. Risk factors for HCC recurrence were evaluated by logistic regression analysis. Recurrence-free survival (RFS) and overall survival (OS) were calculated using Kaplan-Meier analyiss. Statistical significance was defined as $P<0.05$.

\section{Results}

\section{Patient characteristics}

A total of 74 HCC patients was divided into the recurrence group $(n=33,44.6 \%)$ and the nonrecurrence group $(n=41,55.4 \%)$, as shown in Table 1 , under the criteria of the disease states after LT. The median follow-up time was 26.1 months (range from 2.3 to 91 months) in the recurrence group and 71.2 months (range from 8 to 120 months) in the nonrecurrence group, and 28 deaths (37.8\%) were recorded. There was significant difference between the two groups $(P<0.01)$ analyzed by Student's t-test, indicating a close association of the follow-up time and OS with carcinoma recurrence. Moreover, Chi-squared test or Fisher's exact test revealed that the Milan criteria, TNM stage, tumor size, nodules number and microvascular invasion were significant risk factors that involved in recurrence $(P<0.05)$. However, other factors such as age, sex, hepatitis B, cirrhosis, Child-Pugh grading, tumor differentiation, pre-LT serum AFP level, and antineoplastic prophylaxis after LT failed to influence patient recurrence events $(P>0.05)$.

\section{Rap 1 A genotype distribution and its association with HCC recurrence}

The minor allele frequencies (MAFs) of Rap1A rs494453 genotypes in both donors and recipients were more than 0.01 , which were calculated by Hardy-Weinberg equilibrium. When comparing the recipients and donors carring Rap1A rs494453 polymorphisms, the latter presented distinct distributions in recurrence and nonrecurrence group while the former did not show significance, as shown in Table 2. It is of note that patients who received donor Rap1A rs494453 AG/GG genotype experienced a significantly higher recurrence rate after LT than those received
AA genotype $(78.8 \%$ vs. $21.2 \%, P=0.001)$. However, the Rap1A rs494453 genotypes of recipients did not influence the incidence rates of HCC recurrence after LT.

Table 1. Clinicopathological characteristics and two groups of the HCC patients

\begin{tabular}{|c|c|c|c|}
\hline Parameter & $\begin{array}{l}\text { Recurrence group } \\
(n=33)\end{array}$ & $\begin{array}{l}\text { Nonrecurrence group } \\
(\mathrm{n}=41)\end{array}$ & P value \\
\hline Recipient age & $47(33-64)$ & $49(32-66)$ & 0.689 \\
\hline \multicolumn{4}{|l|}{ Recipient sex } \\
\hline Male & $30(90.9 \%)$ & $35(85.4 \%)$ & \\
\hline Female & $3(9.1 \%)$ & $6(14.6 \%)$ & 0.468 \\
\hline Follow up time(month) & $26.1(2.3-91)$ & $71.2(8-120)$ & $<0.001$ \\
\hline \multicolumn{4}{|l|}{ Hepatitis B } \\
\hline Yes & $29(87.9 \%)$ & $39(95.1 \%)$ & \\
\hline No & $4(12.1 \%)$ & $2(4.9 \%)$ & 0.257 \\
\hline \multicolumn{4}{|l|}{ Cirrhosis } \\
\hline Yes & $24(72.7 \%)$ & $35(85.4 \%)$ & \\
\hline No & $9(27.3 \%)$ & $6(14.6 \%)$ & 0.179 \\
\hline \multicolumn{4}{|l|}{ Child-Pugh grading } \\
\hline A & $20(60.6 \%)$ & $27(65.9 \%)$ & \\
\hline $\mathrm{B}+\mathrm{C}$ & $13(39.4 \%)$ & $14(34.1 \%)$ & 0.641 \\
\hline \multicolumn{4}{|l|}{ Histologic grade } \\
\hline Well+moderately & $27(81.8 \%)$ & $37(90.2 \%)$ & \\
\hline Poorly & $6(18.2 \%)$ & $4(9.8 \%)$ & 0.292 \\
\hline \multicolumn{4}{|l|}{ Milan criteria } \\
\hline Within & $4(12.1 \%)$ & $25(61.0 \%)$ & \\
\hline Beyond & $29(87.9 \%)$ & $16(39.0 \%)$ & $<0.001$ \\
\hline \multicolumn{4}{|l|}{ TNM stage } \\
\hline $1-2$ & $4(12.1 \%)$ & $26(63.4 \%)$ & \\
\hline $3-4$ & $29(87.9 \%)$ & $15(36.6 \%)$ & $<0.001$ \\
\hline \multicolumn{4}{|l|}{ Tumor size(cm) } \\
\hline$<5$ & $13(39.4 \%)$ & $31(75.6 \%)$ & \\
\hline$\geq 5$ & $20(60.6 \%)$ & $10(24.4 \%)$ & 0.002 \\
\hline \multicolumn{4}{|l|}{ Number of nodules } \\
\hline$<3$ & $19(58.8 \%)$ & $33(79.6 \%)$ & \\
\hline$\geq 3$ & $14(41.2 \%)$ & $8(20.4 \%)$ & 0.032 \\
\hline \multicolumn{4}{|l|}{ Microvascular invasion } \\
\hline Yes & $19(58.8 \%)$ & $3(7.3 \%)$ & \\
\hline No & $14(41.2 \%)$ & $38(92.7 \%)$ & $<0.001$ \\
\hline \multicolumn{4}{|l|}{ Pre-LT serum AFP level } \\
\hline$\leq 400(\mathrm{ng} / \mathrm{ml})$ & $25(75.8 \%)$ & $28(68.3 \%)$ & \\
\hline$>400(\mathrm{ng} / \mathrm{ml})$ & $8(24.2 \%)$ & $13(31.7 \%)$ & 0.479 \\
\hline \multicolumn{4}{|c|}{ Antineoplastic prophylaxis after LT } \\
\hline Yes & $8(24.2 \%)$ & $3(7.3 \%)$ & \\
\hline No & $25(75.8 \%)$ & $38(92.7 \%)$ & 0.120 \\
\hline
\end{tabular}

\section{Risk factors for HCC recurrence after LT by logistic regression analysis}

As previous studies reported that AFP level and histologic grade also reflect the recurrence rate, we included the two predictive factors into the logistic regression analysis. Univariate logistic regression analysis was carried out. We found that the Milan criteria, TNM stage, tumor size, nodules numbers, microvascular invasion and donor Rap1A rs494453 genotypes turn out to be significant determinants for HCC recurrence after LT. To avoid collinearity, the tumor size and nodule numbers were excluded and the remaining variables indeed had no collinearity (tolerance $>0.1$ ). Multivariate logistic analysis revealed that $\mathrm{TNM}$ stage $(\mathrm{OR}=6.444,95 \%$ CI 2.671-26.679; 
$P=0.007)$, microvascular invasion $(\mathrm{OR}=20.283,95 \% \mathrm{CI}$ 3.277-125.527; $P=0.001)$, Milan criteria $(\mathrm{OR}=5.924,95 \%$ CI 1.379-25.446; $P=0.017$ ) and donor Rap1A rs494453 genotypes $(\mathrm{OR}=12.014,95 \% \mathrm{CI}$ 2.351-61.401; $P=0.003$ ) were associated with HCC recurrence (Table 3 ).

\section{Association between donor rs494453 polymorphisms and survival rates}

The Rap1A rs494453 genotype polymorphisms of donors, but not the recipients mainly contributed to the recurrence differences in both RFS and OS by univariate Cox regression analysis. The RFS and OS of recipients carring donor's AA, AG and GG alleles were further analysed by Kaplan-Meier survival and the log-rank test to distinguish the effect of different donor rs494453 polymorphism on prognosis. Distinctions of the AG, AA and GG genotypes of donors were observed on RFS and OS of recipients ( $P=0.001$ and $P=0.049$, respectively; Fig. $1 \mathrm{~A}$ and $1 \mathrm{~B})$. In addition, the RFS and OS of recipients with AG/GG genotypes of donor group were dramatically decreased compared to those with AA genotype $(P<0.001$ and $P=0.007$, respectively; Fig. $2 \mathrm{~A}$ and $2 \mathrm{~B})$. However, recipient rs494453 genotypes did not show the influence on RFS and OS differentially (S1 A and B and $\mathrm{S} 2 \mathrm{~A}$ and $\mathrm{B})$.
Table 2. Donor and recipient RaplA genotype distribution and the association with $\mathrm{HCC}$ recurrence

\begin{tabular}{|c|c|c|c|c|}
\hline & \multicolumn{2}{|c|}{ Genotype distribution, $\mathbf{n}(\%)$} & \multirow[t]{2}{*}{$P$ value } & \multirow{2}{*}{$\begin{array}{l}\text { HWE } \\
\text { value }\end{array}$} \\
\hline & Recurrence(n=33) & Nonrecurrence(n=41) & & \\
\hline \multicolumn{5}{|c|}{ Donor rs494453 } \\
\hline GG & $8(24.3 \%)$ & $3(7.3 \%)$ & & 0.056 \\
\hline AG & $18(54.5 \%)$ & $12(29.3 \%)$ & 0.497 & \\
\hline AA & $7(21.2 \%)$ & $26(63.4 \%)$ & 0.003 & \\
\hline \multicolumn{5}{|c|}{ Dominant model } \\
\hline AA & $7(21.2 \%)$ & $26(63.4 \%)$ & & \\
\hline AG/GG & $26(78.8 \%)$ & $15(36.4 \%)$ & 0.001 & \\
\hline \multicolumn{5}{|c|}{ Recessive model } \\
\hline GG & $8(24.2 \%)$ & $3(7.3 \%)$ & & \\
\hline AG/AA & $25(75.8 \%)$ & $38(92.7 \%)$ & 0.201 & \\
\hline \multicolumn{5}{|c|}{ Additive model } \\
\hline AG & $18(54.5 \%)$ & $12(29.3 \%)$ & & \\
\hline AA/GG & $15(45.5 \%)$ & $29(70.7 \%)$ & 0.062 & \\
\hline \multicolumn{5}{|c|}{ Recipient rs494453 } \\
\hline GG & $7(21.2 \%)$ & $8(19.5 \%)$ & & 0.853 \\
\hline AG & $22(66.7 \%)$ & $27(65.9 \%)$ & 0.904 & \\
\hline AA & $4(12.1 \%)$ & $6(14.6 \%)$ & 0.993 & \\
\hline \multicolumn{5}{|c|}{ Dominant model } \\
\hline AA & $4(12.1 \%)$ & $6(14.6 \%)$ & & \\
\hline AG/GG & $29(87.9 \%)$ & $35(85.4 \%)$ & 0.988 & \\
\hline \multicolumn{5}{|c|}{ Recessive model } \\
\hline GG & $7(21.2 \%)$ & $8(19.5 \%)$ & & \\
\hline AG/AA & $26(78.8 \%)$ & $33(80.5 \%)$ & 0.998 & \\
\hline \multicolumn{5}{|c|}{ Additive model } \\
\hline AG & $22(66.7 \%)$ & $27(65.9 \%)$ & & \\
\hline AA/GG & $11(33.3 \%)$ & $14(34.1 \%)$ & 0.956 & \\
\hline
\end{tabular}

HCC: hepatocellular carcinoma; HWE: Hardy-Weinberg equilibrium.

Table 3. Univariate and Multivariate logistic regression analysis of risk factors associated with HCC recurrence

\begin{tabular}{|c|c|c|c|c|}
\hline \multirow[t]{2}{*}{ Variables } & \multicolumn{2}{|l|}{ Univariate analysis } & \multicolumn{2}{|l|}{ Multivariate analysis } \\
\hline & Odds ratio(95\%CI) & $P$ value & Odds ratio $(95 \% \mathrm{CI})$ & $P$ value \\
\hline Recipient age $(0 \leq 50,1>50)$ & $1.21(0.51-2.77)$ & 0.609 & & \\
\hline Recipient sex ( 0 female, 1 male) & $1.66(0.37-7.65)$ & 0.421 & & \\
\hline Hepatitis B(0 No, 1 Yes) & $0.51(0.16-2.55)$ & 0.367 & & \\
\hline Cirrhosis(0 No,1 Yes) & $0.53(0.16-1.58)$ & 0.201 & & \\
\hline Child-Pugh grade (0 Grade A, 1 Grade $B+C$ ) & $1.21(0.52-2.77)$ & 0.733 & & \\
\hline Histologic grade ( 0 well + moderately, 1 poorly) & $3.01(0.81-10.55)$ & 0.123 & & \\
\hline Pre-LT serum AFP level $(0 \leq 400 \mathrm{ng} / \mathrm{ml}, 1>400 \mathrm{ng} / \mathrm{ml})$ & $0.744(0.25-2.23)$ & 0.566 & & \\
\hline TNM stage $(0$ stage $1-2,1$ stage $3-4)$ & $8.33(2.38-24.88)$ & 0.003 & $6.444(2.671-26.679)$ & 0.007 \\
\hline Tumor size $(\mathrm{cm})(0<5,1 \geq 5)$ & $4.54(1.76-11.09)$ & 0.011 & & \\
\hline Number of nodules $(0<3,1 \geq 3)$ & 2.54(1.11-7.01) & 0.042 & & \\
\hline Microvascular invasion(0 No, 1 Yes) & $14.12(4.54-47.12)$ & $<0.001$ & $20.283(3.277-125.527)$ & 0.001 \\
\hline Milan criteria( 0 within, 1 beyond $)$ & $7.44(2.32-23.01)$ & 0.002 & $5.924(1.379-25.446)$ & 0.017 \\
\hline Donor Rap1A rs494453 genotype (0 AA, 1 AG/GG) & $2.211(1.114-5.898)$ & 0.009 & $12.014(2.351-61.401)$ & 0.003 \\
\hline
\end{tabular}

CI: confidence interval.

A

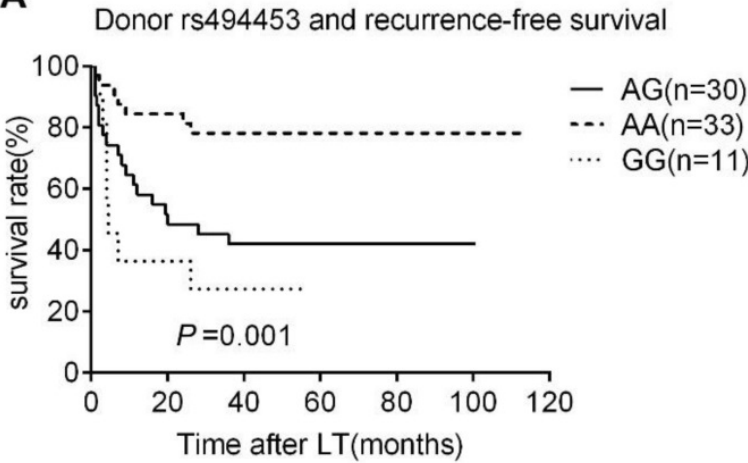

B

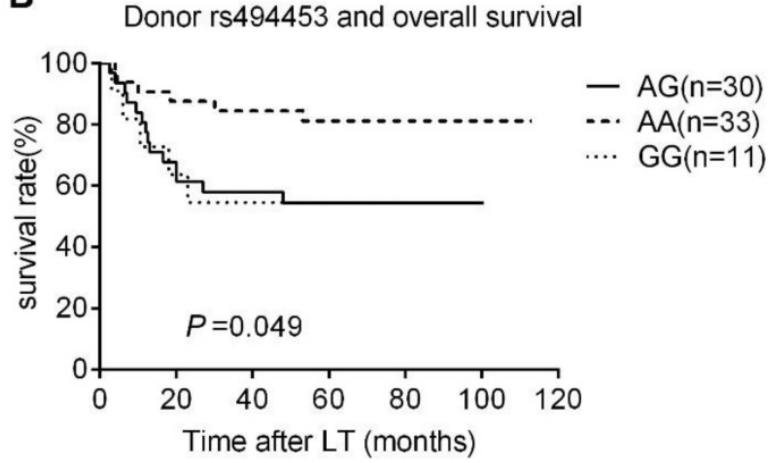

Figure 1. Kaplan-Meier survival estimates of recurrence-free survival (RFS) (A) and overall survival (OS) (B) among different donor genotypes (AA, GG, and AG). Patients carrying donors genotype GG and AG had the most lower RFS and OS. 
A

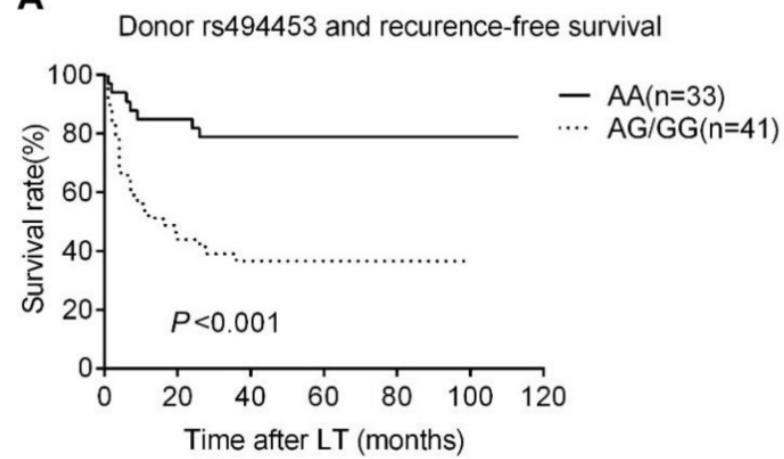

B

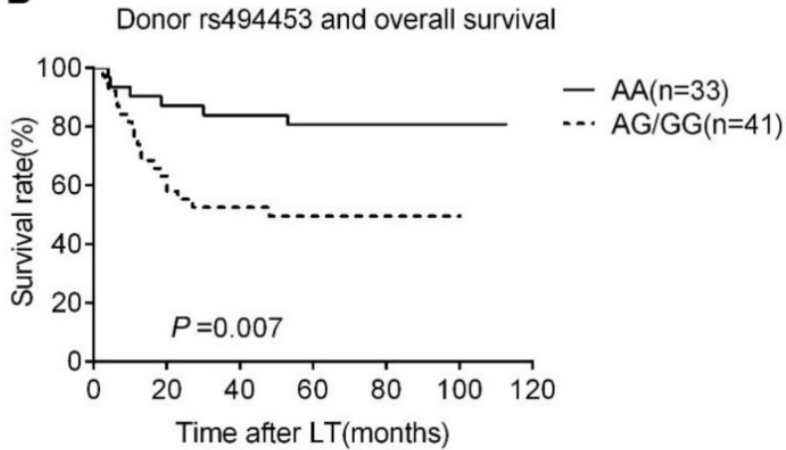

Figure 2. Kaplan-Meier survival estimates of recurrence-free survival (RFS) (A) and overall survival (OS) (B) between different donor genotypes (AA vs. AG/GG). Patients carrying donor homozygous AG/GG had a significantly lower RFS and OS than AA patients.

Table 4. Cox regression analysis of the risk factors for recurrence-free survival rate

\begin{tabular}{|c|c|c|c|c|}
\hline \multirow[t]{2}{*}{ Variables } & \multicolumn{2}{|l|}{ Univariate analysis } & \multicolumn{2}{|l|}{ Multivariate analysis } \\
\hline & $\begin{array}{l}\text { Hazard ratio } \\
(95 \% \mathrm{CI})\end{array}$ & $P$ value & $\begin{array}{l}\text { Hazard ratio } \\
(95 \% \mathrm{CI})\end{array}$ & $\begin{array}{l}P \\
\text { value }\end{array}$ \\
\hline $\begin{array}{l}\text { Pre-LT serum AFP level } \\
(>400 \mathrm{ng} / \mathrm{ml})\end{array}$ & $0.812(0.355-1.867)$ & 0.821 & & \\
\hline $\begin{array}{l}\text { Histologic grade } \\
\text { (poorly) }\end{array}$ & $1.621(0.668-3.930)$ & 0.285 & & \\
\hline TNM stage (stage3-4) & $7.669(2.681-21.940)$ & $<0.001$ & $16.004(2.047-125.110)$ & 0.008 \\
\hline Tumor size $(\geq 5 \mathrm{~cm})$ & $3.633(1.777-7.429)$ & $<0.001$ & & \\
\hline Number of nodules $(\geq 3)$ & $2.206(1.103-4.409)$ & 0.025 & & \\
\hline Milan criteria (beyond) & $6.754(2.363-19.301)$ & $<0.001$ & $3.936(1.228-12.614)$ & 0.021 \\
\hline Microvascular invasion & $5.950(2.919-12.129)$ & $<0.001$ & $3.046(1.394-6.657)$ & 0.005 \\
\hline $\begin{array}{l}\text { Donor rs } 494453 \\
\text { AG/GG genotype }\end{array}$ & $2.596(1.034-6.515)$ & 0.002 & $3.430(1.474-7.981)$ & 0.004 \\
\hline
\end{tabular}

Table 5. Cox regression analysis of the risk factors for overall survival rate

\begin{tabular}{|c|c|c|c|c|}
\hline \multirow[t]{2}{*}{ Variables } & \multicolumn{2}{|l|}{ Univariate analysis } & \multicolumn{2}{|l|}{ Multivariate analysis } \\
\hline & $\begin{array}{l}\text { Hazard ratio } \\
(95 \% \mathrm{CI})\end{array}$ & $\begin{array}{l}P \\
\text { value }\end{array}$ & $\begin{array}{l}\text { Hazard ratio } \\
(95 \% \mathrm{CI})\end{array}$ & $\begin{array}{l}P \\
\text { value }\end{array}$ \\
\hline $\begin{array}{l}\text { Pre-LT serum AFP level } \\
(>400 \mathrm{ng} / \mathrm{ml})\end{array}$ & $1.177(0.511-2.976)$ & 0.605 & & \\
\hline $\begin{array}{l}\text { Histologic grade } \\
\text { (poorly) }\end{array}$ & $1.209(0.443-3.23)$ & 0.787 & & \\
\hline Milan criteria(beyond) & $4.182(1.432-12.207)$ & 0.013 & & \\
\hline Tumor size $(\geq 5 \mathrm{~cm})$ & $2.606(1.168-5.814)$ & 0.019 & & \\
\hline Number of nodules $(\geq 3)$ & 2.794(1.271-6.139) & 0.011 & & \\
\hline TNM stage(stage3-4) & $23.862(3.220-176.823)$ & 0.002 & $11.490(1.432-92.192)$ & 0.022 \\
\hline Microvascular invasion & 7.797(3.396-17.901) & $<0.001$ & $3.638(1.532-8.638)$ & 0.003 \\
\hline $\begin{array}{l}\text { Donor rs } 494453 \\
\text { AG/GG genotype }\end{array}$ & $2.460(1.155-5.240)$ & 0.020 & $2.816(1.104-7.181)$ & 0.030 \\
\hline
\end{tabular}

\section{Risk factors for recurrence-free survival rate and overall survival rate by Cox regression analysis}

We selected more impressive factors to perform multivariate Cox regression analysis, including pre-LT serum AFP level (>400ng/ml), histologic grade (poorly differentiated), TNM stage (stages $3-4$ ), tumor size $(\geq 5 \mathrm{~cm})$, number of nodules $(\geq 3)$, Milan criteria (beyond), microvascular invasion and donor rs1927914 AG/GG genotype, and once again excluded tumor size and the number of nodules to prevent collinearity, as mentioned above. The remaining variables showed no collinearity (tolerance $>0.1)$. The Milan criteria $(\mathrm{HR}=3.936,95 \% \mathrm{CI}$ 1.228-12.614; $P=0.021)$, TNM stage $(\mathrm{HR}=16.004,95 \%$ CI 2.047-125.110; $P=0.008)$, microvascular invasion (HR=3.046, 95\% CI 1.394-6.657; $P=0.005)$, and donor rs494453 AG/GG genotype $(\mathrm{HR}=3.430,95 \% \mathrm{CI}$ 1.474-7.981; $P=0.004$ ) were found to be independent risk factors for RFS (Table 4). Additionally, for overall survival, the TNM stage (HR=11.490, 95\% CI 1.43292.192; $P=0.022)$, microvascular invasion $(\mathrm{HR}=3.638$, $95 \%$ CI 1.532-8.638; $P=0.003)$, and donor rs494453 AG/GG genotype (HR=2.816, 95\% CI 1.104-7.181; $P=0.030$ ) were also considered as independent risk factors (Table 5).

\section{Discussion}

Rap1A is a GTPase that belongs to the Ras-associated protein (Rap) family, which is similar to Ras mostly [16], and associated with cancer initiation and progression [10]. Rap1A plays a molecular switch role by converting the inactive GDP-bound state to an active GTP-bound state [17]. In previous studies, Rap1A gene over-expression had been reported in various cancers, including ovarian cancer [10], breast cancer [18], and OCSCC [13]. The relationship between SNP genotype and HCC recurrence after LT has been reported in VEGF gene [19], IL-15 gene [20] and HPSE gene [21], signifying that the SNP genotype of hosts, including recipients and donors, has a significant role in the progression of HCC recurrence after LT.

In this study, we explored whether the genetic variations of Rap1A were associated with the HCC recurrence after LT. Our results demonstrated that polymorphisms of donor Rap1A rs494453 were remarkably significant in the prediction of HCC recurrence after LT by Kaplan-Meyer curve analysis. Additionally, the increased risk of HCC recurrence was accompanied with AG/GG genotype of donors. Multivariate analysis showed that TNM stage, Milan 
criteria, microvascular invasion and the donor Rap1A rs494453 genotype AG/GG were considered as independent risk factors for HCC recurrence and RFS. In addition, the TNM stage, microvascular invasion and the donor Rap1A rs494453 genotype AG/GG were independent risk factors for OS. These results were consistent with those of previous studies $[7,22,23]$.

However, the mechanism about how the genetic variation of Rap1A increased the recurrence risk remains unknown. Rap1A encoded protein regulates signaling pathways that affect cell proliferation and adhesion, which plays a role in tumor malignancy. $\mathrm{MO}$ et al. found that TNF-a activated NF-kB pathway promotes Rap1A protein over-expression then further increases the HCC progression and metastasis [14]. Tao et al. found that Rap1A activates the MAPK signaling pathway to develop breast cancer [24]. Other studies also showed that Rap1A promotes cell proliferation and metastasis by activating the extracellular signal-regulated kinase (ERK) and regulating the integrin-mediated cellular activities $[25,26]$. Regarding our results, the microvascular invasion influenced mostly on HCC recurrence, which may be explanded by the circulating tumor cells from microvascular tumor thrombus $[27,28]$.

The limitations of our study were embodied in the two respects. The first limitation was the little patient sample amount with $80.9 \%$ of it having HBV related liver disease. To obtain more reliable results, it is needed to expand the patient's sample amount and take in more HCC samples caused by different pathogenic factors, except for HBV. Besides, although we have concluded that the variant genotype influenced HCC recurrence of patients after LT surgery, there is a need to investigate the function and mechanism of Rap1A rs494453 in HCC recurrence.

In conclusion, this is the first investigation on the relationship of Rap1A gene rs494453 polymorphisms in HCC patients treated with LT. These results concluded the positive relationship between donor Rap1A rs494453 polymorphisms with HCC recurrence and OS of LT patients. Furthermore, Rap1A rs494453, microvascular invasion and Milan criteria actively predicted the risk of HCC recurrence after liver LT. These findings could be used for the clinical prognosis of liver transplantation.

\section{Supplementary Material}

Supplementary figures.

http://www.jcancer.org/v11p3082s1.pdf

\section{Acknowledgements}

This work was supported in part by the National Natural Science Foundation of China under grant numbers 81401956 and 81702341 , and by the Medical Engineering Crossing Project Grant from Shanghai Jiao Tong University (grant number: YG2016QN24). The funding agencies had no role in study design, data collection and analysis, decision to publish, or preparation of the manuscript.

\section{Competing Interests}

The authors have declared that no competing interest exists.

\section{References}

1. Ferlay J, Soerjomataram I, Dikshit R, et al. Cancer incidence and mortality worldwide: sources, methods and major patterns in GLOBOCAN 2012. Int J Cancer. Mar 1 2015;136(5):E359-386.

2. Lee KK, Kim DG, Moon IS, Lee MD, Park JH. Liver transplantation versus liver resection for the treatment of hepatocellular carcinoma. J Surg Oncol. Jan 1 2010;101(1):47-53.

3. Lee S, Hyuck David Kwon C, Man Kim J, et al. Time of hepatocellular carcinoma recurrence after liver resection and alpha-fetoprotein are important prognostic factors for salvage liver transplantation. Liver Transpl. Sep 2014;20(9):1057-1063.

4. Andreou A, Bahra M, Schmelzle M, et al. Predictive factors for extrahepatic recurrence of hepatocellular carcinoma following liver transplantation. Clin Transplant. Jul 2016;30(7):819-827.

5. Kondili LA, Lala A, Gunson B, et al. Primary hepatocellular cancer in the explanted liver: outcome of transplantation and risk factors for HCC recurrence. Eur J Surg Oncol. Sep 2007;33(7):868-873.

6. Lai Q, Avolio AW, Lerut J, et al. Recurrence of hepatocellular cancer after liver transplantation: the role of primary resection and salvage transplantation in East and West. J Hepatol. Nov 2012;57(5):974-979.

7. Nagai S, Yoshida A, Facciuto M, et al. Ischemia time impacts recurrence of hepatocellular carcinoma after liver transplantation. Hepatology. Mar 2015;61(3):895-904.

8. Mazzaferro V, Chun YS, Poon RT, et al. Liver transplantation for hepatocellular carcinoma. Ann Surg Oncol. Apr 2008;15(4):1001-1007.

9. Chen J, $\mathrm{Xu} \mathrm{X}, \mathrm{Wu} \mathrm{J}$, et al. The stratifying value of Hangzhou criteria in liver transplantation for hepatocellular carcinoma. PLoS One. 2014;9(3):e93128.

10. Lu L, Wang J, Wu Y, Wan P, Yang G. Rap1A promotes ovarian cancer metastasis via activation of ERK/p38 and notch signaling. Cancer Med. Dec 2016;5(12):3544-3554.

11. Xiang J, Bian C, Wang H, Huang S, Wu D. MiR-203 down-regulates Rap1A and suppresses cell proliferation, adhesion and invasion in prostate cancer. J Exp Clin Cancer Res. Jan 31 2015;34:8.

12. Sayyah J, Bartakova A, Nogal N, Quilliam LA, Stupack DG, Brown JH. The Ras-related protein, Rap1A, mediates thrombin-stimulated, integrin-dependent glioblastoma cell proliferation and tumor growth. J Biol Chem. Jun 20 2014;289(25):17689-17698.

13. Chen $\mathrm{CH}$, Chuang $\mathrm{HC}$, Huang CC, et al. Overexpression of Rap-1A indicates a poor prognosis for oral cavity squamous cell carcinoma and promotes tumor cell invasion via Aurora-A modulation. Am J Pathol. Feb 2013;182(2):516-528.

14. Mo SJ, Hou X, Hao XY, et al. EYA4 inhibits hepatocellular carcinoma growth and invasion by suppressing NF-kappaB-dependent RAP1 transactivation. Cancer Commun (Lond). Apr 3 2018;38(1):9.

15. Gabriel S, Ziaugra L, Tabbaa D. SNP genotyping using the Sequenom MassARRAY iPLEX platform. Curr Protoc Hum Genet. Jan 2009;Chapter 2:Unit 212.

16. Bos JL, de Rooij J, Reedquist KA. Rap1 signalling: adhering to new models. Nat Rev Mol Cell Biol. May 2001;2(5):369-377.

17. Zhang Z, Mitra RS, Henson BS, et al. Rap1GAP inhibits tumor growth in oropharyngeal squamous cell carcinoma. Am J Pathol. Feb 2006;168(2):585-596.

18. Ahmed SM, Theriault BL, Uppalapati M, et al. KIF14 negatively regulates Rap1a-Radil signaling during breast cancer progression. J Cell Biol. Dec 10 2012;199(6):951-967.

19. Wu LM, Xie HY, Zhou L, Yang Z, Zhang F, Zheng SS. A single nucleotide polymorphism in the vascular endothelial growth factor gene is associated with recurrence of hepatocellular carcinoma after transplantation. Arch Med Res. Oct 2009;40(7):565-570.

20. Zhang T, Liu Y, Peng X, Fan J, Peng Z. Association between Recipient IL-15 Genetic Variant and the Prognosis of HBV-Related Hepatocellular Carcinoma after Liver Transplantation. Dis Markers. 2017;2017:1754696.

21. Yu L, Zhang X, Zhai Y, et al. Association of polymorphisms in the heparanase gene (HPSE) with hepatocellular carcinoma in Chinese populations. Genet Mol Biol. Oct-Dec 2017;40(4):743-750.

22. Chen D, Liu S, Chen S, et al. Donor interleukin 6 gene polymorphisms predict the recurrence of hepatocellular carcinoma after liver transplantation. Int J Clin Oncol. Dec 2016;21(6):1111-1119. 
23. Zhang Y, Shi ZL, Yang X, Yin ZF. Targeting of circulating hepatocellular carcinoma cells to prevent postoperative recurrence and metastasis. World J Gastroenterol. Jan 7 2014;20(1):142-147.

24. Zhang $\mathrm{T}$, Jiang $\mathrm{K}$, Zhu X, et al. miR-433 inhibits breast cancer cell growth via the MAPK signaling pathway by targeting Rap1a. Int J Biol Sci. 2018;14(6):622-632.

25. Dorn A, Zoellner A, Follo M, et al. Rapla deficiency modifies cytokine responses and MAPK-signaling in vitro and impairs the in vivo inflammatory response. Cell Immunol. Mar-Apr 2012;276(1-2):187-195.

26. Pizon V, Baldacci G. Rap1A protein interferes with various MAP kinase activating pathways in skeletal myogenic cells. Oncogene. Dec 7 2000;19(52):6074-6081.

27. Kelley RK, Magbanua MJ, Butler TM, et al. Circulating tumor cells in hepatocellular carcinoma: a pilot study of detection, enumeration, and next-generation sequencing in cases and controls. BMC Cancer. Mar 31 2015;15:206.

28. Zhang YL, Wang RC, Cheng K, Ring BZ, Su L. Roles of Rap1 signaling in tumor cell migration and invasion. Cancer Biol Med. Feb 2017;14(1):90-99. 